\title{
Potential for false positive HIV test results with the serial rapid HIV testing algorithm
}

Steven Baveewo ${ }^{1 *}$, Moses R Kamya', Harriet Mayanja-Kizza', Robin Fatch³ ${ }^{3}$ David R Bangsberg ${ }^{4}$, Thomas Coates ${ }^{5}$, Judith A Hahn ${ }^{3}$ and Rhoda K Wanyenze ${ }^{2}$

\begin{abstract}
Background: Rapid HIV tests provide same-day results and are widely used in HIV testing programs in areas with limited personnel and laboratory infrastructure. The Uganda Ministry of Health currently recommends the serial rapid testing algorithm with Determine, STAT-PAK, and Uni-Gold for diagnosis of HIV infection. Using this algorithm, individuals who test positive on Determine, negative to STAT-PAK and positive to Uni-Gold are reported as HIV positive. We conducted further testing on this subgroup of samples using qualitative DNA PCR to assess the potential for false positive tests in this situation.

Results: Of the 3388 individuals who were tested, 984 were HIV positive on two consecutive tests, and 29 were considered positive by a tiebreaker (positive on Determine, negative on STAT-PAK, and positive on Uni-Gold). However, when the 29 samples were further tested using qualitative DNA PCR, 14 (48.2\%) were HIV negative.

Conclusion: Although this study was not primarily designed to assess the validity of rapid HIV tests and thus only a subset of the samples were retested, the findings show a potential for false positive HIV results in the subset of individuals who test positive when a tiebreaker test is used in serial testing. These findings highlight a need for confirmatory testing for this category of individuals.
\end{abstract}

Keywords: False positive, HIV testing algorithm, Rapid diagnostic tests, Qualitative PCR testing

\section{Background}

Rapid HIV tests provide quick results [1], usually in less than 30 minutes, can be performed by any adequately trained health worker, do not require sophisticated equipment and can be stored at room temperature $\left(20^{\circ} \mathrm{C}\right.$ $\left.30^{\circ} \mathrm{C}\right) ;[2]$. Yet, their diagnostic accuracy has been found to be comparable to that of Enzyme Linked Immunosorbent Assay (ELISA) [1,3]. These advantages make the rapid HIV tests suitable for use in geographically remote areas with little or no laboratory infrastructure and in small hospitals that perform few HIV tests [4]. Determine and Uni-Gold have a sensitivity of $100 \%[5,6]$ and STATPAK is $97.7 \%$ [7] sensitive. The specificities for Determine, Uni-Gold and STAT-PAK are 99.75\% [5], 99.7\% [6] and $99.9 \%$ [7] respectively. Despite the high sensitivity

\footnotetext{
* Correspondence: baveewosteven@yahoo.co.uk

'Department of Medicine, Makerere University School of Medicine, Kampala, Uganda

Full list of author information is available at the end of the article
}

and specificity, rapid diagnostic tests have a rare potential for false negative and false positive test results [8].

The World Health Organization HIV retesting guidelines [9] highlight the criteria for retesting persons with indeterminate and negative HIV test results in order to reduce the likelihood of false negative HIV results in early HIV infection [9]. However, these guidelines do not address the potential for false positive HIV results. This paper sought to identify the potential for false positive results in the serial HIV testing algorithm of DetermineSTAT-PAK-Uni-Gold, specifically in the subset of individuals who tested positive on Determine, negative on STAT-PAK, and positive on Uni-Gold, by conducting further testing using Deoxyribonucleic acid Polymerase chain reaction Qualitative (DNA PCR QL) testing.

\section{Methods}

\section{Study procedures}

The study was conducted as part of the HIV VCT and Linkage to Care study in Mulago hospital [10]; a research
C Biomed Central

C 2012 Baveewo et al; licensee BioMed Central Ltd. This is an open access article distributed under the terms of the Creative Commons Attribution License (http://creativecommons.org/licenses/by/2.0), which permits unrestricted use, distribution, and reproduction in any medium, provided the original work is properly cited. 
collaboration between Makerere University, University of California Los Angeles (UCLA) and University of California San Francisco (UCSF).

Adult patients ( $\geq 18$ years) who had never tested for HIV, or tested negative at least 1 year prior to recruitment and willing to receive a HIV test were eligible [11]. Ethical approval was obtained from the collaborating institutions' Ethical Review boards as well as Uganda National Council of Science and Technology and each participant provided verbal and written informed consent prior to enrolment into the study.

\section{Laboratory testing}

HIV counseling and testing was offered after enrollment and baseline interview. Following pre-test counseling, the counselor contacted the laboratory technician to draw blood for HIV testing [11]. HIV testing was done using the serial testing algorithm using the Determine (Abbott Laboratories, Abbott Park, IL), STAT-PAK (Chembio Diagnostics), and Uni-Gold ${ }^{\mathrm{TM}}$ Recombigen $^{(}{ }^{(\text {Figure } 1) .}$ Subjects that tested HIV negative on Determine were reported as negative. Subjects that tested positive on Determine, negative on STAT-PAK and negative on UniGold were also reported as negative. According to the national algorithm, samples that tested positive on Determine, negative on STAT-PAK and then positive on a Uni-Gold (tie-breaker test) would be reported as positive and not retested. However, we conducted further testing of the latter samples using Deoxyribonucleic acid Polymerase chain reaction Qualitative (DNA PCR QL) tests

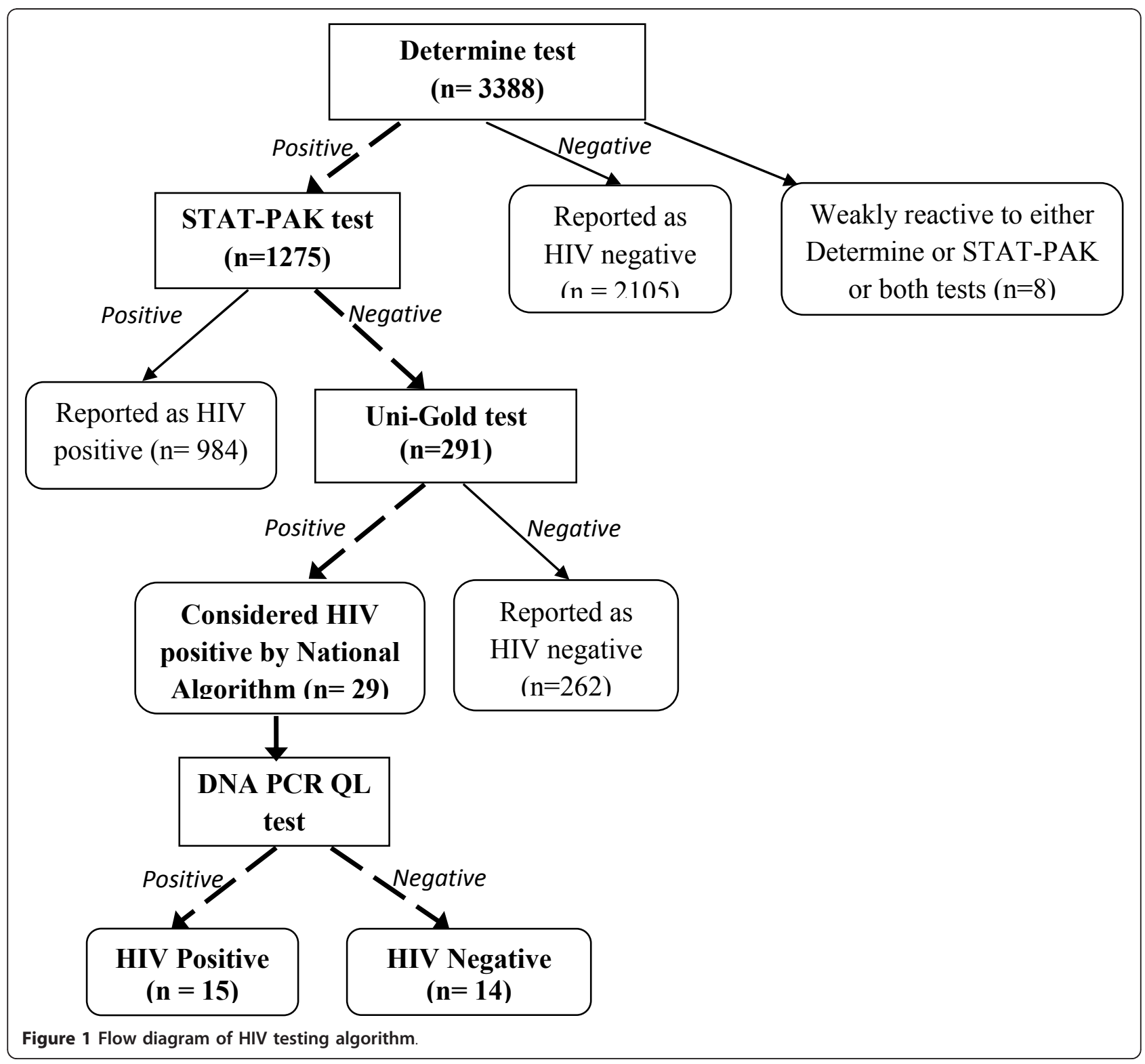


(Ampiclor HIV-1 DNA PCR Test version 1.5) [12]. The 29 samples that tested positive with the tie breaker were not retested with rapid tests before the DNA PCR QL testing.

\section{Statistical analysis}

Data captured in a Microsoft Excel spreadsheet was exported to SAS program for statistical analysis.

\section{Results}

Overall, 3,388 individuals were tested for HIV between May 2008 and June 2011 and 1004 (29.6\%) tested HIV positive (Figure 1). Twenty-four percent of men and $34 \%$ of women were HIV positive. Two thirds $(62.1 \%$, n $=2105$ ) of individuals tested negative on Determine and were reported as negative. Of the 1275 that tested positive on Determine, 984 also tested positive on the STAT-PAK and were reported as positive, while 291 were negative on STAT-PAK and were retested with Uni-Gold. Of the 291 that were retested with Uni-Gold, 262 tested negative and were reported as negative; and 29 tested positive. The 29 samples were further tested using DNA PCR QL, and 14 (48.2\%) tested HIV negative. DNA PCR has a very high specificity of $99.5 \%$, [95\% CI 99.1-99.9], and is thus an ideal choice for identifying false positive results $[13,14]$. Eight participants who were weakly reactive to the Determine and/or STAT-PAK test were also further tested using DNA PCR QL, but were not included among the false positive results in this study since they would have been retested with ELISA, according to the current national algorithm [15].

\section{Discussion}

These findings show potential for false positive HIV test results in the subset of individuals who tested positive on Determine, negative on STAT-PAK and positive on Uni-Gold ${ }^{\mathrm{TM}}$. DNA PCR QL test may result in occasional false positives but not false negatives [8], which implies that the HIV negative DNA PCR QL results in this study are likely to be accurate. Misdiagnosis of HIV can lead to psychological difficulties and psychiatric morbidity, has public health and epidemiological implications and can lead to medico-legal conflict, and should thus be avoided to the extent possible [16].

This study is limited in that it was not primarily designed to evaluate the validity of rapid HIV test results. Since only individuals with positive tie-breaker tests were further tested using DNA PCR QL, we cannot estimate the overall false positive rate. However, these findings highlight an important subgroup of individuals that require confirmatory testing with DNA PCR or other highly specific test. There is need for further studies to examine the occurrence of false positive HIV test results and mechanisms for minimizing this challenge.

Conclusion Individuals who test positive on Determine, negative on STAT-PAK and positive on Uni-Gold should be considered inconclusive and be further tested using DNA PCR QL or other validated tests to minimize the occurrence of false positive HIV test results.

\section{Acknowledgements}

We thank the participants, the study team and the management of Mulago hospital.

Funding

This study was funded by National Institute of Mental Health (1 R01 MH077512), Division of AIDS and Health and Behavior Research, Center for Mental Health Research on AIDS. The funders had no role in the study design, data collection and analysis, decision to publish, or preparation of the manuscript.

\section{Author details}

${ }^{1}$ Department of Medicine, Makerere University School of Medicine, Kampala, Uganda. ${ }^{2}$ Department of Disease Control and Environmental Health, Makerere University School of Public Health, Kampala, Uganda. ${ }^{3}$ Department of Medicine San Francisco General Hospital, University of California San Francisco, San Francisco, California, USA. ${ }^{4}$ Massachusetts General Hospital Center for Global Health and Harvard Medical School, Boston, Massachusetts, USA. ${ }^{5}$ Division of Infectious Diseases, David Geffen School of Medicine, University of California Los Angeles, Los Angeles, California, USA.

\section{Authors' contributions}

Conceived, designed and performed the experiments; SB, MRK, HMK, RF, DBR, TC, HJA, RWK. Analyzed the data: SB, RF, JAH. Contributed reagents/ materials/analysis tools: SB, MRK, HMK, RF, DBR, TC, HJA, RWK. Wrote the paper, proof read and approved the final manuscript: SB, MRK, HMK, RF, DBR, TC, JAH and RWK.

\section{Competing interests}

The authors declare that they have no competing interests.

Received: 4 October 2011 Accepted: 19 March 2012

Published: 19 March 2012

\section{References}

1. Kassler WJ, Alwano-Edyegu MG, Marum E, Biryahwaho B, Kataaha P, et al: Rapid HIV testing with same-day results: a field trial in Uganda. Int J STD AIDS 1998, 9(3):134-138.

2. Rapid HIV tests: Guidelines for use in HIV testing and counseling services in resource constrained settings. 2004 [http://www.emro.who.int/aiecf/ web28.pdf].

3. Stetler HC, Granade TC, Nunez CA, Meza R, Terrell S, et al: Field evaluation of rapid HIV serologic tests for screening and confirming HIV-1 infection in Honduras. AIDS (London, England) 1997, 11(3):369-375[http://www.ncbi. nlm.nih.gov/pubmed/9147429].

4. UNAIDS/WHO: Guidelines for using HIV testing technologies in Surveillance: Selection, Evaluation and Implementation.Geneva: UNAIDS/WHO. WHO/CDS/ CSR/EDC/2001.16 UNAIDS/01.22E 2001 [http://data.unaids.org/Publications/ IRC-pub02/jc602-hivsurvguidel_en.pdf].

5. Determine HIV $1 / 2$ rapid test. [http://www.b-i-p.co.th/events/pdf/Package\% 20Insert\%20Determine\%20HIV\%20eng.pdf], [Cited.

6. Uni-Gold ${ }^{\mathrm{TM}}$ Recombigen ${ }^{\circledR}$ HIV. [http://www.fda.gov/downloads/ BiologicsBloodVaccines/BloodBloodProducts/ApprovedProducts/ PremarketApprovalsPMAs/ucm093428.pdf], [Cited.

7. Chembio HIV 1/2 STAT-PAKTM: Assay Summary of Safety and Effectiveness [http://www.fda.gov/downloads/biologicsbloodvaccines/ bloodbloodproducts/approvedproducts/premarketapprovalspmas/ ucm173137.pdf], [Cited.

8. Murphy $R$, Peters V, Gill B, Dominguez $K$, Thomas $P$, et al: Predictive value of HIV-1 DNA PCR in perinatally HIV-exposed infants born 1997-2002 in NYC XVth International AIDS Conference: Bangkok, Thailand; 2004. 
9. WHO: Delivering HIV test results and messages for retesting and counseling in adults 2010 [http://www.searo.who.int/LinkFiles/HIV-AIDS_re_testing.pdf].

10. Providing Voluntary HIV Counseling and Testing Plus Linkage to Care in Uganda available on web. [http://clinicaltrials.gov/ct2/show/NCT00648232].

11. Wanyenze RK, Kamya MR, Fatch R, Mayanja-Kizza H, Baveewo S, et al: Missed opportunities for HIV testing and late-stage diagnosis among HIV-infected patients in Uganda. PloS One 6(7):e21794[http://www. plosone.org/article/info\%3Adoi\%2F10.1371\%2Fjournal.pone.0021794].

12. Piwowar-Manning E, Lugalia L, Kafufu B, Jackson JB: Comparison of results obtained with Amplicor HIV-1 DNA PCR test version 1.5 using 100 versus 500 microliters of whole blood. J Clin Microbiol 2008, 46(3):1104-1105.

13. WHO: Report of the WHO Technical Reference Group, Paediatric HIV/ART Care Guideline Group Meeting Geneva: WHO; 2008, 13[http://www.who.int/hiv/ pub/paediatric/WHO_Paediatric_ART_guideline_rev_mreport_2008.pdf].

14. Owens DK, Holodniy M, McDonald TW, Scott J, Sonnad S: A meta-analytic evaluation of the polymerase chain reaction for the diagnosis of HIV infection in infants. Jama 1996, 275(17):1342-1348.

15. Ministry of Health: Uganda National Policy Guidelines for HIV Counseling and Testing. 2005, 18-20[http://www.who.int/hiv/pub/guidelines/ uganda_art.pdf].

16. Bhattacharya R, Barton S, Catalan J: When good news is bad news: psychological impact of false positive diagnosis of HIV. AIDS Care 2008, 20(5):560-564.

\section{doi:10.1186/1756-0500-5-154}

Cite this article as: Baveewo et al: Potential for false positive HIV test results with the serial rapid HIV testing algorithm. BMC Research Notes 2012 5:154

\section{Submit your next manuscript to BioMed Central and take full advantage of:}

- Convenient online submission

- Thorough peer review

- No space constraints or color figure charges

- Immediate publication on acceptance

- Inclusion in PubMed, CAS, Scopus and Google Scholar

- Research which is freely available for redistribution

Submit your manuscript at www.biomedcentral.com/submit 